\title{
The convergence of National Professional Qualifications in educational leadership and masters level study
}

\section{Abstract \\ Purpose}

In February 2012, less than three years after the introduction of the compulsory National Professional Qualification for Headship (NPQH) for aspiring school head teachers, the mandatory requirement was removed. Despite no longer being a requirement, nearly 900 individuals annually, successfully complete the programme, with a further 5,000 completing the awards of National Professional Qualification for Middle Leadership (NPQML) and the National Professional Qualification for Senior Leadership (NQPSL).

In 2017, the UK government decided that the suite of national professional qualifications (NPQML, NPQSL, NPQH) needed to be updated in order to ensure that they remained relevant to the changing shape of the educational landscape, particularly through the expansion of multi-academy trusts. At the same time, the government proposed a new National Professional Qualification for Executive Leadership (NPQEL) aimed at the chief executives of multi-academy trusts, which vary in size from two or three schools working together, to trusts with in excess of thirty five schools.

This paper explores the way in which the new NPQ programmes are having masters level criteria embedded into them to facilitate a seamless progression into masters level study and what potential benefits this brings to the individual and the provider of the NPQ programmes.

\section{Design/methodology/approach}

The paper combines desk research with reflections on the experience of developing the new NPQ programme within higher education institutions (HEls) and considers the implications of this upon current and emerging $\mathrm{HEl}$ practice and research into educational leadership.

\section{Findings}

There were a number of key issues highlighted by the paper. Notably the process of embedding academic criteria into a training programme, which was not previously used to support the notion of critical reflection. In addition the associated mechanisms of accreditation, existing professional networks and the upskilling of staff delivering the NPQ programme, and a professionally oriented interface between the university, employer and deliverer of the training.

\section{Originality/value}

This paper provides an original perspective involving the embedding of masters level criteria into professional qualifications in the field of educational leadership. 


\section{The convergence of National Professional Qualifications in educational leadership and masters level study}

Keywords: educational leadership, national professional qualifications, head teachers, schools, work based learning.

\section{Introduction}

The teaching profession, for schools in England, has historically been tightly regulated with specific training comprising of the achievement of academic qualifications delivered by higher education institutions (HEIs) followed by the successful completion of a mandatory year of on-the-job training before becoming a fully qualified teacher. Despite the structured programme of training and support needed to become a teacher, there is a well-documented crisis in recruiting individuals into the profession (Taylor, 2014). Furthermore, Howson (2014) stated that $40 \%$ of teachers leave the profession within their first five years of teaching while Jones (2014) suggests that fewer than $11 \%$ of individuals want to make the transition from classroom teacher into formal leadership roles within English schools. The National Professional Qualifications (NPQ) has long been part of the government's support for individuals who aspire to leadership positions in UK schools. These qualifications are unique to the schools' sector, and are positioned between work-based qualifications, such as National Vocational Qualifications (NVQs) which demonstrate an individual's competency at completing to a minimum standard designated tasks and professional qualifications, such as those offered by professional bodies, for example, the Chartered Management Institute (CMI) which are predominantly designed for knowledge acquisition.

The NPQ qualifications do not confer Chartered or qualified status, granted by an organisation approved to do so by means of a Royal Charter or approval by the UK government's Privy Council. Nor does it provide a license to practise from a professional body but as a suite of qualifications, they comprise both knowledge as well as the requirement to apply this knowledge in the individual's own school. The qualifications are designed to support the development of individuals from middle leadership with the National Professional Qualifications for Middle Leadership (NPQML) through to senior leadership with the National Professional Qualifications for Senior Leadership (NPQSL) and finally onto headship with the National Professional Qualifications for Headship (NPQH). From 2008 the NPQH programme was mandatory for all individuals who were twelve to eighteen months from gaining their first appointment as head teachers in UK schools and optional for those already in post. It was aimed at developing the skills necessary to lead a complex organisation such as a school but ostensibly focused on leading pupil behaviour, developing leadership skills and managing teacher performance rather than the skills of leading a multi-million pound organisations such as financial and risk management or governance. The programme also required individuals to undertake a whole school leadership project in a placement school but often these focused on teaching and learning which is just one aspect of the role of the head teacher.

The 2010 political reform of education removed the mandatory requirement for individuals to hold the NPQH award as part of the then Conservative-Liberal Democrat coalition government's desire to remove the bureaucratic burden which has increasingly been placed on schools. Underpinning this removal of this requirement is a backdrop of a declining number of individuals pursuing headship (NATH, 2015). As a result of the changing educational landscape, Hargreaves and Fink (2006) suggest that increases in job stress, inadequate levels of funding and an increasingly diverse student population are all contributing to a lack of individuals seeking out headship opportunities. Fink 
(2010), however, argues that the shortage of individuals pursuing senior leadership positions is due to the current generation valuing family life over work and their desire to maintain a healthy worklife balance. Despite the role becoming seemingly less attractive many schools have adopted a succession planning strategy, but as Davies and Davies (2011) argue this is rarely sufficient and institutions need to be considering a talent identification and management programme to ensure that potential leaders are identified and supported from early on in their careers.

Notwithstanding the qualification for headship being no longer a mandatory requirement it is still considered by school governing bodies as an essential part of a school's succession planning strategy. Annually nearly 900 individuals complete the NQPH programme, and a further 5000 completing the awards of National Professional Qualification for Middle Leadership (NPQML) and the National Professional Qualification for Senior Leadership (NQPSL). Yet these awards have no UK recognised awarding organisation accreditation attached to them. However, successful completion is dependent on passing a series of assessed activities and an end of course summative assessment, after which individuals receive a certificate signed by the current UK Secretary of State for Education.

A 2015 survey by the National Association of Head Teachers (NAHT, 2015) found that 15\% of schools that advertised for a head teacher could not recruit to the post, while $72 \%$ had to re-advertise at least once prior to successfully appointing a candidate. The same survey also found that the average UK cost to recruit a head teacher was circa $£ 3,000$, if an individual was successfully appointed after just once advertisement, raising to nearly $£ 10,000$ for multiple re-advertisements. The NAHT (2015) survey reinforces what Hargreaves and Fink (2006) suggest about the lack of individuals wanting to pursue headship. Grummell, Devine and Lynch (2012) remind us that the role of the head teacher is greedy in terms of the expectations of the individual and the challenges that they face when operating in neoliberal education system, predicated on new managerial ideologies of heightened levels of accountability, performance management, financial control and the stimulation of free market principles.

In order to support schools in attracting and developing future leaders the UK government decided in 2017 that the suite of national professional qualifications (NPQML, NPQSL, NPQH) needed to be updated in order to ensure they remained relevant to the changing shape of the educational landscape. Particular due to the expansion of multi-academy trusts (MATs), groups of schools working together, with a single overarching governance structure. At the same time, the government proposed a new National Professional Qualification for Executive Leadership (NPQEL) aimed at the chief executives of these multi-academy trusts, which vary in size from two or three schools working together, to trusts with in excess of thirty five schools.

Underpinning this new development is the desire to deepen the development of educational systems which meet the needs of schools (Lee, 2012; Wall and Perrin, 2015; Wall, 2016a, b; Wall and Jarvis, 2015) by ensuring that the qualifications remain relevant to the changing needs of leadership in education. At a time when there is no funding to support the development of future leaders of education. The difficulties of acquiring such skills directly through mainstream academic curricula are widely documented alongside the opportunities afforded by developing associated tacit or professional knowledge in live environments, such as schools (e.g. see Ng \& Feldman, 2004; Archer \& Davison, 2008; Hughes, Sheen and Birkin, 2013; Billett, 2014). These perspectives echo Schon's (1983) view that there is still too sharp a distinction between an academic qualification and measurement of professional competence. The concept that HEls should work closely with schools to deliver the new suite of national professional qualifications promise to directly tackle the issues around employability and professional competence. These developments emanated from HEls that 
had already established flexible, work-based learning frameworks and extensive links with professional bodies and schools.

This paper therefore offers a review of how a North West of England higher education institution $(\mathrm{HEI})$, responded to the government's policy to support the development of leaders through the redevelopment of the existing NPQ awards. In doing so, the paper examines the collaboration needed to engage in the development, with a government approved deliverer, of the new national professional qualifications in order to converge the academic and professional competencies. The paper offers a reflection on some of the key resources and processes which enabled this development, with a view to support other HEls in developing their own responses.

\section{CHALLENGES FOR HEIS IN DELIVERING NATIONAL PROFESSIONAL QUALIFICATIONS}

The concept of the national professional qualifications is not new, sitting under the heading of workbased learning which has continuously evolved over hundreds of years, and has developed from the learning of traditional trades to embracing qualifications for modern society and the emergent sectors such as IT, retail, customer service and more recently, education. Yet, work-based learning in education is often overlooked, especially when considering more traditional notions of learning, as it covers such a broad spectrum of learning. Included under the heading of work-based learning is everything from apprenticeship at level 2 and level 3 (equivalent to qualifications achieved at aged 16 and 18 in England and Wales) which are delivered by further education colleges (similar to community or technical colleges) or private training organisations, to highly skilled forms of workbased learning such as medicine, surgery, law or architecture. Similarly, individuals who study for professional doctorates in areas such as education or business undertake research that is directly grounded in their work-based professional practice. The education sector has more recently become a staunch deliverer of work-based learning, particularly in initial teacher education, which provides individuals with their initial professional training. Recently initial teacher education has moved away from traditional HEl based deliverer with placements in schools, to a model of either sole school based delivery or with a significant majority of training delivered in schools and a small minority of HEI delivery, echoing Schon's (1983) idea around the distinction between academic and competency based learning. There is, however, a shift happening in the form of degree apprenticeships. Introduced by the UK government in 2016 in order to increase the number of individuals participating in apprenticeship programmes to their aspiration of 3 million by 2020, they are not without their challenges. Issues of accountability and the quality of these new programmes continue to be unresolved (Lambert, 2016). What degree apprenticeships will hopefully achieve, and it is too early to tell, is accelerate the convergence between academic and work-based learning.

The national professional qualifications are another example of work-based learning delivered by licensed (government approved) deliverers, which may or may not be HEIs. Typically, providers of the NPQ qualifications could be groups of schools that deliver initial teacher education programmes, national organisations whose sole business is the delivery of the NPQ programmes or HEls. As of October 2017, 57 organisations were licensed to deliver the one or more of the NPQ programmes, 10 of which were licensed to deliver the programme nationally, with the other 47 operating in one or more regions in England. While 57 organisations do not seem many, it is worth noting that these figures mask the true number of actual deliverers. These 57 organisations are ones that have contracts for the delivery of these qualifications in England with the UK government's Department for Education (DfE), many of which will have numerous 'delivery partners' delivering the qualifications on behalf of the licensee. In some instances, 50 or more delivery partners could be 
involved in the delivery of qualifications in different geographical areas all operating under one licensee. Only 4 of the 57 licensees have an obvious connection to an HEI, but this does not mean others do not, as a vast majority have branding designed to instil a level of confidence to the consumer. For example, using the words, 'outstanding', 'quality' or 'inspiring leadership', or have branding which emphases the local area in which they deliver, possibly capitalising on an already established reputation.

Despite the varying organisations involved in the delivery of a nationally set curriculum for the different NPQ awards, there remains a lack of higher education endorsement of the programmes. HEls will allow individuals with NPQ awards, entry with advance standing into postgraduate qualifications through institutional derived accreditation of prior learning processes, which usually involve individuals demonstrating their understanding of the theories that underpin their learning. This requirement to demonstrate their understanding reinforces the disconnect between academic and professional competency. Yet this divergent nature is not unique to the NPQ suite of awards but is systematic of work-based learning per se. For example, the common inference that work based learning and notably apprenticeships equals "stacking shelves" (Wallop and Williams, 2013) or "making coffee" (Ofsted, 2015). While these examples are both outdated and not relevant to higher education based programmes, the traditional perception of the significant portion of work-based learning being second class, as opposed to what might be argued as being a programme for the most highly able and driven professionals of tomorrow. It is not inconceivable that it is these prejudices that have deterred NPQ deliverers from working with HEls and conversely HEls, many of which are trapped by their traditional ways of doing things (Handscombe, 2003) from wanting to recognise the value to the education sector of working more closely with deliverers of the NPQ awards.

National Professional Qualifications sit uncomfortably within these existing notions of work-based learning. For example, they fall into the category of initial professional training, for those individuals moving from a predominantly teaching and learning function within their school, to one that focuses on leadership. At the same time, they are also part of an individual's structured career development programme, as entry to the programme and indeed to leadership in schools, is often restricted to those who have worked in a teaching role. This potentially results in an identity crisis for deliverers of the NPQ programme in terms of where it sits within the topology of work-based learning. As a result, it becomes difficult to reconcile where these programmes fit in terms of academic recognition. For example, undergraduate courses are often perceived as initial professional training, which the NPQ could legitimately be. Yet, at the same time, they are career development programmes, which are often at postgraduate level. In addition, as these are courses with a leadership focus, are they positioned within faculties of business or education?

Successive governments have driven the requirement for HEls to develop entrepreneurial activities, but HEI responses have been varied depending upon their 'entrepreneurial architectures' (Nelles \& Vorley, 2008). This is hindered by organisational structures that HEI adopt which are usually predicated on specialist faculties which to some extent maintain a degree of autonomy from the rest of the organisation. This culture of isolation and fragmentation is difficult to change (Johnson, et al., 2014) and many become trapped by their traditional ways of working, often requiring much internal lobbying to facilitate innovation (Handscombe, 2003). It is becoming increasingly apparent that this lack of flexibility and entrepreneurship has led to a lack of engagement with NPQ deliverers.

Bravenboer and Lester (2016) argue that there is a presumption that academic learning and professional competence are different enough in nature to preclude them being recognised through the same qualification or assessment process. Within HEls, academics argue that whilst work-based learning might be appropriate in certain subject areas such as business and management, some 
more scientific subject areas could suffer from a manipulation of content and lack objectivity (Barnett, 2002; Gillis and McNally, 2010). Additionally, some opportunities or projects may not be seen as of equal worth or academically credible (Lester and Costley, 2010) which may lead to workbased learning being seen to represent a threat to the existing portfolio of courses. That said, pragmatically, by engaging in work-based learning such as the NPQ programme, HEls could see an increase in progression onto postgraduate study albeit with advanced standing through masters level credits gained via the completion of NPQ programme.

A further issue facing HEls is regarding resource and internal expertise. Plewa, Galan-Muros \& Todd (2015) have found that the engagement of businesses in developing the curriculum is highly valuable, however this cannot be simply limited to one or two superficial activities. The NPQ programmes clearly have huge potential to provide progression onto postgraduate studies resulting in increased income. Nonetheless their inception is difficult and time consuming that requires highlevel negotiation skills, alongside the ability to write and map appropriate curriculum content which meets the nationally set NPQ standards and individual delivery partners' needs into existing masters level provision. The HEI which is the focus of this paper also took the decision to incorporate Chartered Management Institute (CMI) leadership qualifications into the NPQ programme, where participants benefit from gaining a widely-recognised general management qualification although this does lead to a plethora of learning outcomes needing to be met. Unfortunately, and not uniquely, $\mathrm{HEI}$ resource devoted to the development of such programmes is often scarce, and frequently left to one of two individuals who have the vision and foresight to see the benefit of such collaboration.

At the time of the redevelopment of the NPQ qualifications the prime minster, Theresa May announced an unexpected general election, resulting in significant delays, due to the period of government silence known simply as 'purdah', in the announcement of which organisations had successfully been granted licences to deliver the revised NPQ qualifications. This delay forced potential deliverers to do one of two things. One was to place an unintentional halt on critical activity until after purdah, the other being to continue in the development of the curriculum, at the HEl's and potential deliverers' own risk. The final announcement on the awarding of the licences was not until the first week in July 2017, with delivery of the new NPQs expected from September 2017 as per the original timeline. In addition, interested deliverers have no guidelines in terms of the new curriculum, simply a set of overarching principles, which placed an additional pressure on HEls and licensees in terms of ensuring that the programmes offered from September 2017 are relevant to the changing needs of educational leadership.

\section{EXPERIENCES OF DEVELOPING THE NEW NATIONAL PROFESSIONAL QUALIFICATIONS}

Notwithstanding the issues discussed earlier, the publication of new national professional qualification suite of standards has resulted in significant change in curriculum compared to the previous incarnation of the qualifications. The implication of this has been a heavy investment in time in both creating a market for these new courses by the licensee, and jointly with the HEl in the redesign of the curriculum. Despite working with an established deliverer of the old qualifications, any income potential for the $\mathrm{HEl}$ as a result of progression onto accredited post-graduate programmes is at least a further 12 months away. There is also the need to align to existing or create new modules, which presents a challenge for many HEls. Typically the process will involve the mapping of the new NPQ standards onto existing modules and the development of multiple new modules along with the alignment of professional body standards. For some HEls this may involve the attainment of full programme approval, although as a faculty this has been avoided through the careful mapping and writing of content to ensure that it maps onto as many existing modules as possible and through the creation of a minimal number of new modules. The validation of the new 
programme was also a possibility, and was precluded, at an early stage, due to the timescale of bringing a new postgraduate programme that integrated the new NPQ programmes to market, alongside the rigidity of HEls in terms of pricing of courses in line with market expectations and issues of quality assurance of licensed deliverers. Particularly, when the government expects the new NPQ awards to be delivered by the schools' sector and not by higher education institutions. Although this may pose many challenges, it is possible to adapt and build upon existing provision, in particular, where work-based learning opportunities have been developed for students on traditional programmes of study (Major, Meakin and Perrin, 2011).

The development of this type of work-based provision together with continued interest from central government in encouraging links between $\mathrm{HE}$ and industry has led a number of universities to develop academic frameworks focused on work-based learning (WBL) for learners already in employment. The development of these frameworks in the UK has been underpinned for over a decade by successive government reports, for example, the Dearing Report (1997), the Lambert Report (2003) and the Leitch Review (2006). These frameworks typically bring together pedagogy and independent learning (Lester and Costley, 2010; Wall, 2015) with a focus on the fostering and assessment of capability (Stephenson and Weil, 1992).

When located within the modular, credit-based system, HEls are able to provide flexible learning opportunities across a wide range of professional areas for learners in the workplace. This is because of the work of an increasing number of HEls in developing wide-ranging frameworks for negotiated work-based learning, which enable the granting of academic credits from experiential learning where students are able to demonstrate their workplace capability. In this context, many universities have found that the development of programmes such as the NPQ awards can be done from a solid base from which the academic infrastructure can facilitate the development, alongside the recognition that a culture. This acknowledges that much of the knowledge capital exists outside of the higher education. Therefore, the emergence of the new national professional qualifications should not be seen as so much as a threat (either in terms of unfamiliar pedagogy or as potentially undermining recruitment onto more traditional educational leadership routes) but as an opportunity building on universities existing strengths and reputation. One of the most significant factors in facilitating the development of the new national professional qualifications is a commitment to working collaboratively with the approved licensee and acknowledging their experience in facilitating the previous version of NPQ programmes alongside the reputation of the HEl in delivering the educational leadership to learners from across England. This experience seemed to act as a foundation to build structural capital, capable of fulfilling the needs of the licensee and ultimately schools (Garnett, 2009; Garnett, et al., 2008). It is important to note that some HEls, particularly those with a history of similar developments, will have experience of developing a significant number of customised work-related modules specifically designed to meet the needs of commissioners or employers by blending online materials with periodic workshops that could enable learning to be applied in the workplace. These modules, plus work-based learning frameworks which allow for the negotiation of work-based projects contextualised to an individual's work place setting, for example, primary, secondary and special schools, are critical building blocks in the development of the new programme.

Established networks were equally as important in the development, not just of the NPQ programme but more widely when collaborating on any form of work-based learning. The University, which this paper focuses on, has worked with an existing NPQ licensee, for two years albeit on an informal basis. The licensee has been successfully delivering the NPQ programmes in the North West and East of England regions since 2012. As part of their strategic development the licensee was seeking to 
expand its delivery network of schools which act as delivery hubs to have a national presence. Up to this point, individuals successfully completing one of the NPQ awards (NPQML, NPQSL, NPQH) would have to, if they wanted to progress onto masters level study, complete a portfolio of evidence ranging from 5000 words to 10000 words in order to demonstrate the underpinning theories that supported the learning on the NPQ programmes. This was felt by many students as unrealistic given the learning that they had already undertaken. The licensee wanted a programme that was a true reflection of the learning that takes place in the workplace, but that was also flexible enough to meet the challenges of leading complex organisations such as schools.

An initial review of the University's existing educational leadership module descriptors revealed a high correlation between the learning outcomes of the modules and the requirements of the NPQ programmes. Because of the flexibility and sheer number of modules available within the educational leadership programme and the flexibility of the negotiated work-based learning modules, it was possible to effectively develop and cross-map nearly two thirds of an MA in Educational Leadership for the licensee and to include an embedded Chartered Management Institute (CMI) level 7 award in strategic leadership and management.

This was achieved by considering the 3 elements of each NPQ programme which are the same across the programmes and mapping the 'knowledge expectations' of each theme to learning outcomes within the MA modules (Diagram 1). This ensured that there was alignment between the two programmes, prior to suggestions being made on the content that needed to be delivered in order the meet the requirements of both programmes.

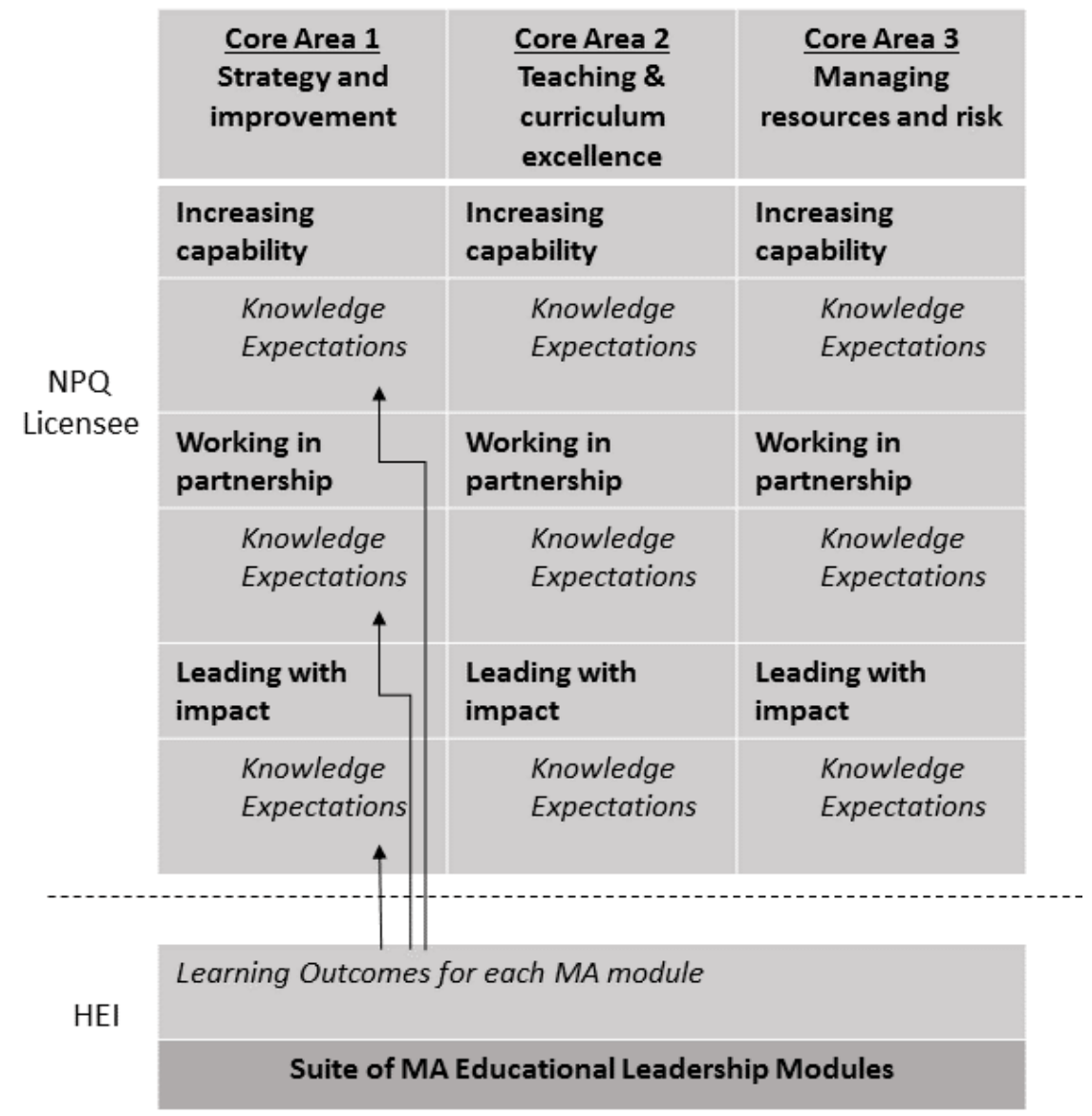

Diagram 1 - Visual representation of the NPQ and MA programme. 
Academic regulations prohibited the mapping the full MA in Educational Leadership, as this would have required complex partnership arrangements with individual delivery partners, currently in excess of 50 nationally. As a faculty, there was a desire to ensure that faculty staff facilitated some of the learning, particularly when it came to the 60 credit dissertation, in part due to the concern of whether practitioners had sufficient research and supervisory experience and capacity to deliver high quality masters level dissertations. This was a less of a concern for the taught modules due to the significant involved of the university in the writing of the content, ensuring that the necessary theoretical concepts were sufficiently developed through the resources and blended learning materials. What has been created is a unique postgraduate offering in the UK for aspiring educational leaders, which brings together the academic understanding from the MA in Educational with the competency-based learning from NPQ awards and the externality from the CMI level 7 award which can offer an additional progression opportunity to Chartered Manager status.

The first cohort on the new NPQ awards commenced in September 2017; however, the university will not see the seamless progressions without the need for students to undertake the additional substantial written element until at least September 2018. Such a thorough alignment is testament to the collaborative approach taken by the university and the NPQ licensee and the ability to rapidly develop and deliver a highly relevant, employer-led programme with added value embedded throughout.

Whilst many schools espouse the benefits of national professional qualification, in reality their primary concern is how study time will affect an individual's ability to maintain their current leadership responsibilities within school and whether additional masters level study will add any value. Yet the benefits of the NPQ programme and masters level study have converged, mitigating Schon's (1983) concerns around the distinction between academic and competency-based learning. Whether these new programmes will reverse the trend in head teacher recruitment that the NAHT (2015) study highlighted, it is too early to say, but individuals will have a better understanding of leadership and the impact that they make as a result of the new NPQ programme.

\section{CONCLUSIONS AND IMPLICATIONS}

In recognising the continued need to support and develop future leaders of education, the new national professional qualification offers an additional opportunity for individuals to engage in a form of higher education which explicitly develops professional competence. By linking the NPQ qualification to that of a professional body brings additional value to a qualification that the education sector is still wedded to, despite them no longer being mandatory. Yet the recent tendering for licences and the re-development of the awards has been challenging. This is due to the speed of the introduction, delays resulting from purdah and the lack of guidance and parameters around the NPQ awards. At the same time, we can see that there are strategic and structural resources within HEls which can serve to support the developments of these programmes. It appears that HEls are working collaboratively to develop flexible work-based learning curricular that responds to both employer and professional body needs. However, building flexibility does not just relate to providing a choice between optional modules within a pre-existing programme, but is more intertwined into the cultural fabric of a HEl this links to pedagogy and even unit level learning experiences (Wall, 2013; Wall and Perrin, 2015). This includes the academic frameworks and associated processes of accreditation, relationships with professionals and professional networks. But one needs to be mindful of the risk associated with collaboration, which should by no means be a barrier, simply that both the reputation of the organisation and individuals should be factored into 
the culture of the organisation to ensure that visionaries within faculties are not unduly exposed when working with partners. This echoes the sentiments of Garnett and colleagues around structural capital, to orient towards the needs of customers (Garnett, 2009; Garnett, et al., 2008).

Akrivou and Bradbury-Huang (2015) argue that if HEls want to create authentic change agents within practice, and therefore meet governmental agendas, such as the national professional qualifications, HEls need to examine and transform their own organisational values, structures, and processes. The aspiration must be to create an educational environment which inculcates such mindsets in and for practice.

The case study presented in this paper indicates that there are communities in HEls which are structured in ways towards this aspiration, but more cases and research are needed to examine how NPQ providers and HEls will work collaboratively together to support schools in jointly developing leadership capacity.

\section{REFERENCES}

Akrivou, K. and Bradbury-Huang, H. (2015), Educating integrated catalysts: Transforming business schools toward ethics and sustainability, Academy of Management Learning \& Education, Vol. 14 No. 2, pp. 222-240.

Archer W. and Davison J. (2008), Graduate employability: what do employers think and want?, London, Council for Industry and Higher Education.

Barnett, M. (2002), University-industry relationships in dentistry: past, present, future, Journal of Dental Education, Vol. 66 No. 10, pp. 1163-1168.

Billett, S. (2014), Integrating learning experiencesacross tertiary education and practice settings: A socio-personal account, Educational Research Review, Vol. 12, pp. 1-13.

Bravenboer, D., and Lester, S. (2016), Towards an integrated approach to the recognition of professional competence and academic learning. Education + Training, Vol. 58 Issue: 4, pp.409-421.

Davies, B. and Davies, B. (2011), Talent management in education. London, SAGE publishing.

Dearing, R. (1997), Higher Education in the Learning Society: Report of the National Committee, London, HMSO/National Committee of Inquiry Into Higher Education.

Fink, D. (2010), The Succession Challenge Building and Sustaining Leadership Capacity through Succession Management. London, SAGE Publishing.

Garnett, J., (2009), "Contributing to the Intellectual Capital of Organisations", in J. Garnett, C. Costley and B. Workman (Eds.), Work based learning: journeys to the core of higher education, London, Middlesex University Press.

Garnett, J., Workman, B., Beadsmoore, A. and Bezencenet, S., (2008), "Developing the structural capital of higher education institutions to support work based learning", in F. Tallantyre (Ed.), Workbased learning: workforce development: connections, frameworks and processes, York, The Higher Education Academy, pp. 18-30.

Gillis, M. and McNally, M. (2010), The influence of industry on dental education, Journal of Dental Education, Vol. 74 No. 10, pp. 1095-1105. 
Grummell, B., Devine, D. and Lynch, K. (2012), New Managerialism in Education

Commercialization, Carelessness and Gender. London, Palgrave Macmillan UK

Handscombe, R.D. (2003), The promotion of an entrepreneurial culture in universities, Industry and Higher Education, Vol. 3 No. 1, pp. 219-222.

Hargreaves, A. and Fink, D. (2006), Sustainable Leadership, US, Wiley.

Howson, J. (2014). School Direct failing to tackle teacher shortages, report warns. Available at http://news.tes.co.uk/b/news/2014/09/25/school-direct-fails-to-tackle-teacher-shortage. Aspx (accessed 27 October 2017)

Hughes, T., Sheen, J. and Birkin, G. (2013), Industry graduate skills needs - Summary report for the National Centre for Universities and Business, CFE Research 2013, available at http://www.ncub.co.uk/reports/cfe.html (accessed 8th July 2017).

Johnson, G., Whittington, R., Scholes, K., Angwin, D., Regner, P. (2014), Exploring Corporate Strategy, 10th edition, London, Pearson Education.

Jones, S. (2014) Career progression in teaching: What's driving UK educators? The Guardian Newspaper Tuesday 29 April 2014.

Lambert, R. (2003), Lambert Review of Business-University Collaboration: Final Report, London, HMSO/HM Treasury.

Lambert, S. (2016) Are current accountability frameworks appropriate for degree apprenticeships?, Higher Education, Skills and Work-Based Learning, Vol. 6 Issue: 4, pp.345-356,

Lee, D. (2012). Apprenticeships in England: an overview of current issues, Higher Education, Skills and Work-Based Learning, Vol. 2 No. 3, pp. $225-239$.

Leitch, S. (2006) Prosperity For All in the Global Economy: Final Report, London, HMSO/HM Treasury.

Lester, S. and Costley, C. (2010), Work-based learning at higher education level: value, practice and critique, Studies in Higher Education, Vol. 35 No.5, pp. 561-575.

Major, D., Meakin, D. and Perrin, D. (2011) Building the capacity of higher education to deliver programmes of work-based learning, Higher Education, Skills and Work-based Learning, Vol. 1 No. 2, pp.118-127.

National Association of Head Teachers (NAHT). (2015), The NAHT school recruitment survey 2015. West Sussex, NAHT.

Nelles, J. and Vorley, T. (2008), Entrepreneurial architecture in UK Higher Education Institutions: Consolidating the Third Mission, 25th DRUID celebration conference.

Ng, T.W.H. and Feldman, D. (2009), How broadly does education contribute to job performance?, Personnel Psychology, Vol 62, pp. 89-134. 
Ofsted (2015), Apprenticeships: developing skills for future prosperity: How well do apprenticeships meet the needs of young people, their employers and the economy? October 2015, No. 150129, available at https://www.gov.uk/government/publications/apprenticeships-developing-skills-forfuture-prosperity (accessed 8th July 2017).

Plewa, C., Galan-Muros, V., and Todd, D. (2015), Engaging business in curriculum design and delivery: a higher education institution perspective, Journal of Higher Education, Vol. 70 No. 1, pp. $35-53$.

Schon, D.A. (1983), The Reflective Practitioner: how professionals think in action, New York, Jossey-Bass.

Stephenson, J. and Wiel, S. (eds.) (1992) Quality in Learning: A Capability Approach in Higher Education, London, Kogan Page.

Taylor, C. (2014). School Direct reforms caused 'instability and turbulence', admits teacher training chief. Available at http://news.tes.co.uk/b/news/2014/04/01/government-moves-to-limitdestabilising-effect-of-school-direct-on-universities.aspx (accessed 29 October 2017).

Wall, T. (2013) Diversity through negotiation, in Bridger, K., Reid, I. and Shaw, J. (Eds) Inclusive Higher Education: An International Perspective on Access and the Challenge of Student Diversity (Management Policy Education), Middlesex, Libri Publishing, pp. 87-98.

Wall, T. (2015) Global Perspectives on Profound Pedagogies, Higher Education, Skills \& Work Based Learning, Vol. 5 No. 4, pp 417-419.

Wall, T. (2016a), Author Response: Provocative Education: From The Dalai Lama's Cat ${ }^{\circledR}$ to Dismal Land ${ }^{\circledR}$, Studies in Philosophy and Education, 11th March 2016, pp. 1-5, 10.1007/s11217-016-9521-8.

Wall, T. (2016b) Žižekian ideas in critical reflection: the tricks and traps of mobilising radical management insight, Journal of Work Applied Management, Vol. 8 No. 1, pp 5-16.

Wall, T. and Jarvis, M. (2015). Business schools as educational provocateurs of productivity via interrelated landscapes of practice, London, Chartered Association of Business Schools, available at http://charteredabs.org/business-schools-as-educational-provocateurs-of-productivity-viainterrelated-landscapes-of-practice/ (accessed 8th July 2017).

Wall, T. and Perrin, D. (2015), Žižek: A Žižekian Gaze at Education, London, Springer.

Wallop, H. and Williams, R. (2013), The Real Apprentices, The Telegraph, 12th August 2013, available at http://www.telegraph.co.uk/finance/jobs/10237741/The-real-apprentices.html (accessed 8th July 2017). 